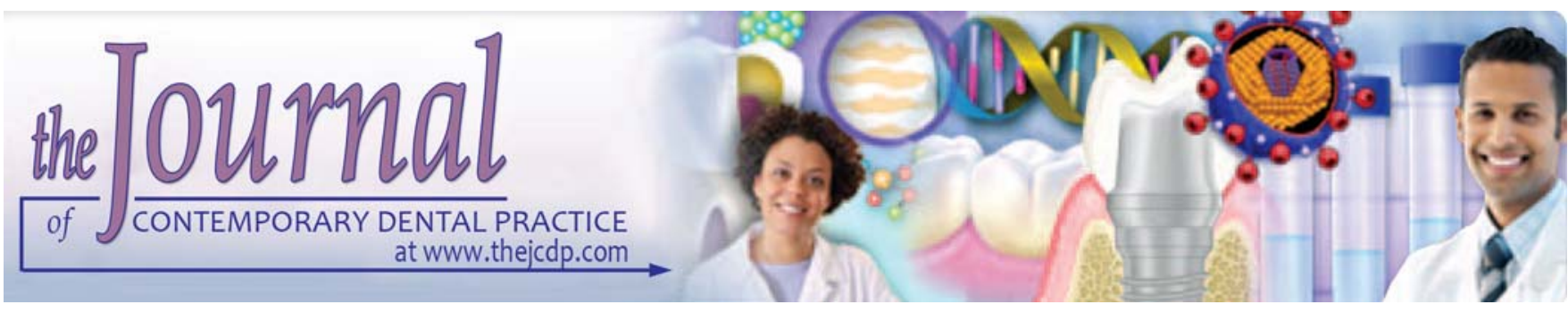

\title{
Review and Update: Advanced Investigation Methods for Diagnosis of Tongue Lesions
}

Neeraj Taneja, Srinivasa Raju, Rajul Mehta, Navdeep Kaur

\begin{abstract}
Various specialized imaging modalities and guided microscopic methods developed in recent years, having proven value for the evaluation of tongue disorders. The list of which includes cineradiography, pulsed ultrasound, computer-assisted tomography, isotopic scanning, electromyography, magnetic resonance, video microscopy and stereo microscopy. The basic aim of the article is to review and throw light on the importance of complete examination of the tongue and application of advanced investigations for the proper diagnosis of the tongue lesions and its usefulness to the clinician.
\end{abstract}

Keywords: Tongue, Tongue lesions, Advanced investigation methods.

How to cite this article: Taneja N, Raju S, Mehta R, Kaur N. Review and Update: Advanced Investigation Methods for Diagnosis of Tongue Lesions. J Contemp Dent Pract 2013;14(2):365-369.

\section{Source of support $\mathrm{Nil}$}

\section{Conflict of interest: None declared}

\section{INTRODUCTION}

The belief that the general health of a person is reflected in his tongue from the days of Hippocrates. ${ }^{1}$ The tongue is meant to be a trustworthy mirror of the health. It performs many functions like prehension and ingestion, suckling, swallowing, phonation and perception of sensations including taste characteristics, thermal changes, pain stimuli and general sensations and helps in jaw development. Traditionally the diagnosis of tongue lesions is always dedicated to the identification of syndromes rather than diseases. Cineradiographic studies help us to understand the position and shape of the tongue in motion. Pulsed (D oppler) ultrasound is used to measure tongue movements in speech and to study the characteristics of arterial blood flow in the tongue. ${ }^{2}$ Computer-assisted tomography (CA T) is used to identify space occupying lesions and muscular atrophy secondary to hypoglossal nerve damage, in cases where the lesion is deep in the base of the tongue and not detectable by other approaches. CA T scan can al so be used for detection of extend of head and neck carcinomas involving tongue and other parts. ${ }^{3}$ I sotopic scanning techniques are used when the tongue is composed of special ized secretory tissue or other tissues, such as thyroid, which selectively concentrates intravenously administered radioactive ${ }^{131}$ or or ${ }^{99} \mathrm{Tc}$-pertechnetate. ${ }^{4}$ Electromyography is a test to evaluate normal functions and al so helps to detect the functional disorders of muscles of the tongue. ${ }^{5} \mathrm{M}$ agnetic resonance imaging (MRI) is used as an alternative to imaging modalities for soft tissue structures, such as the tongue and oropharynx and also helps in assessment of speech sound. ${ }^{6} \mathrm{M} \mathrm{R}$ I has the ability to provide direct coronal or sagittal scanning sections. Scanning electron microscope (SEM) is a well-established tool for in vitro study of the surface topography of tongue dorsum, the character and morphology of the different types of tongue papillae and distribution and morphology of bacteria on the papillated areas of the dorsum. ${ }^{7}$ Video microscopy is useful for observation of the surface of tongue papillae. Stereo microscopy is similar to video microscopy and can be used to study the tongue papillae, their capillary network and taste pores. ${ }^{5}$

\section{EXAMINATION OF TONGUE ${ }^{8,9}$}

\section{Routine Examination}

It includes inspection of dorsum of the tongue while it is at rest for any swelling, ulcers, coating or variation in size, color and texture.

- Careful observation of the distribution of filiform and fungiform papillae, margins of tongue, crenations and fasciculations, depapillated areas, fissures, ulcers and keratotic areas. 
- Lingual frenal attachment and its deviations as the patient protrudes the tongue and attempts to move it to the right and left, should be observed.

- With a wrapped piece of gauze $(4 \times 4 \mathrm{~cm})$ around the tip of the protruded tongue to steady it, and lightly press a warm mirror against the uvula to observe the base of the tongue and vallate papillae.

- The tongue should be gently guided to the right and left, to observe the entire lateral border of the tongue for ulcers, keratotic areas, red patches and the foliate papillae. This is to be repeated to the opposite side.

- Careful examination of the ventral surface of the tongue and floor of the mouth.

- The patient should touch the tip of the tongue to palate.

- The muscles of the tongue to be palpated gently for nodules and tumors, extending the finger onto the base of the tongue and pressing forward if this has been poorly visualized or if any ulcers or masses are suspected.

\section{SPECIALIZED EXAMINATION PROCEDURES}

\section{Cineradiography}

Cineradiography studies the oral cavity and pharynx during drinking, chewing, suckling, phonation and other activities helps us understand the position and shape of the tongue in motion and also help us to diagnose abnormalities of swallowing, phonation and other functions associated with congenital and surgically induced defects.

B rowny et al did a cineradiography in 20 postpolio syndrome patients to eval uate swallowing defects and found positive results and found that the abnormalities were seen in the pharynx in varying degree in all. But, in one of the patient they observed that dysphasia can occur as a late complication to poliomyelitis and cineradiography and flow radiography are useful technique to assess the severity of the disease and degree of decomposition. ${ }^{10}$ The visual inspection of speech articulation possible with high speed, $X$-ray motion-picture photography suggests the attempted fitting of pseudo speech continue to 'corresponding' speech articulation sequences, not only in the specific interest of improving the acoustic quality of simulated speech, with especial reference to timing phenomena, but also in the consequent general increase of knowledge about speech analysis, and as a contrivance for acoustically matching sustained articulation instants. A coustically simulated 'steady-state isolated vowels' and corresponding slides of typical articulatory instants are presented as an introduction to a demonstration of high speed cineradiography of vowels uttered in isolation augmented with matching pseudo speech continue. $^{2}$

\section{Pulsed (Doppler) Ultrasound}

Ultrasound is a form of mechanical acoustic pressure wave at frequencies above the limit of human hearing that when transmitted through biological tissues can produce different biological effects. Noninvasive ultrasound technique has recently been applied study laryngeal activity, pharyngeal wall displacement and tongue movements. Two types of echo ultrasound equipment can be used to monitor tongue movements in speech, A scan and sector scan. In the A scan method, ultrasound pulses are passed from a transducer positioned below the chin, through the skin and the muscular tissue of the tongue, and are reflected in proportion to changes in acoustic impedance, at transitions in tissue density in the tongue body, at the interface between the tongue dorsum and the ambient air, and at the oral cavity walls. The most widely used applications in medicine are operative (usually has a frequency that ranges between 2-8 K Hz), therapeutic (usually has a frequency that ranges between $20 \mathrm{~K} \mathrm{~Hz}-3 \mathrm{M} \mathrm{Hz}$ either in continuous or pulsed modes), and diagnostic (usually has a frequency that ranges between 1.6-12 $\mathrm{M} \mathrm{Hz})^{3}$

It has been used to study the characteristics of arterial blood flow in the tongue, and abnormal pulse waves have been noted in the lingual arteries of individuals with evidence of compromised flow in other branches of the carotid arterial tree. K aren M . Hiiemae and J effrey B. Palmer in 2003 reviewed tongue moments in feeding and speech through ultrasound and stated that it is clear that new and very sophisticated ultrasound technology can generate the data to produce 3D models of the tongue surface. ${ }^{4}$

Donna $T$ Geddes et al in 2008 described the tongue movement and intraoral vacuum in 20 breastfeeding infants through ultrasound and concluded that ultrasound imaging demonstrated that milk flow from the nipple into the infant's oral cavity coincided with both the lowering of the infants tongue and peak vacuum. Therefore vacuum is likely to play a major role in milk removal from the breast. ${ }^{11}$

Recording tongue movements with ultrasound is noninvasive and has not been shown to have any biologic effects in humans at diagnostic intensities. As a result it is possible to record a substantial number of samples, each the duration of a typical utterance. A lso, pulsed ultrasounds particularly enable to on-line computerized measurements and analysis techniques. ${ }^{12}$

\section{Computer-Assisted Tomography}

The CT system was invented in 1972 by Godfrey N ewbold Hounsfield of EM I Central Research Laboratories. In this $\mathrm{X}$-ray slice data is generated using an $\mathrm{X}$-ray source that 
rotates around the object, $\mathrm{X}$-ray sensors are positioned on the opposite side of the circle from the $X$-ray source. $M$ any data scans are progressively taken as the object is gradually passed through the gantry. They are combined together by the mathematical procedure known as tomographic reconstruction. It can be used to identify space occupying lesions and muscular atrophy secondary to hypoglossal nerve damage, in cases where the lesion is deep in the base of the tongue and not detectable by other approaches. CA T scan can also be used for detection of extend of head and neck carcinomas involving tongue and other parts. ${ }^{13}$ Ryuji M urakami et al in 1997 did a CT and M R study of denervated tongue after radical neck dissection and found that the side of the tongue operated on showed low density on CT scans, and concluded that in patients who have undergone a neck dissection for a malignant process, abnormal imaging findings in the tongue not only might indicate a recurrence of tumor involving the hypoglossal nerve but also suggest the possibility of postoperative change. And emphasize the importance of the denervated tongue in differentiating inflammatory from neoplastic diseases of the tongue. ${ }^{14}$

\section{Isotopic Scanning Techniques}

The principle of obtaining diagnostic information from a visual image of isotope distribution is based on the fact that the uptake of an isotope by abnormal tissue often differs from that by normal, healthy tissue. Sometimes it is more, in some other cases less. Present techniques offer a twodimensional image, somewhat similar to the appearance of $X$-ray absorption as seen on an X -ray picture. It can be used when a mass in the tongue is composed of specialized secretory tissue or other tissue, such as thyroid, which selectively concentrates intravenously administered radioactive ${ }^{131}$ I or ${ }^{99} \mathrm{~T} \mathrm{c}$-pertechnetate. Gallium ${ }^{67} \mathrm{Ga}$ scanning and tumor labeling with radioactive indium and cobalt-bleomycin chelates also have been used to outline the extent of lingual and other oral tumors with varying success. ${ }^{4} \mathrm{~B}$ athi, Taneja and $\mathrm{R}$ ao reported a case of asymptomatic tissue growth on dorsal surface of the tongue, isotopic scanning with ${ }^{99} \mathrm{mTCO} 4$ was done to evaluate the type of tissue mass. ${ }^{14}$

\section{Electromyography}

Electromyography is a test to study the muscle functions. It has been used for many years to study the action potentials in actively contracting muscles and has contributed to an understanding of lingual and masticator muscular function and also in detecting uncoordinated muscular movements in diseases like dyskinesia, dystonia, and various neuromuscular disorders. It is a noninvasive technique. Use of surface electrodes (in earlier techniques thin-needle electrode inserted in the muscle to the studied) have been introduced with considerable success. ${ }^{2} \mathrm{~A}$ ccording to Cheng et al movement of the tongue during normal breathing in awake healthy humans with electromyography and suggested that the patterns of local movement vary between subjects. There is anterior movement of the genioglossus muscle at the level of the epiglottis during inspiration with limited movement in nearby tissue including the geniohyoid, and hence even during respiration tongue behaves as a muscular hydrostat. ${ }^{15}$

M ohammad $\mathrm{H}$ ajiha et al contributed to the field of physiology by being the first to report a suppression of respiratory muscle activity caused by the presence of opioids at a distinct central nervous system motor pool, and the first characterization of the receptor mechanisms underlying this suppression. ${ }^{16}$

\section{Magnetic Resonance Imaging}

M RI used as an alternative to imaging modalities involving radiation. It has proven to be vastly superior in the detail it provides, of soft-tissue structures, such as the tongue and oropharynx..$^{5} \mathrm{MRI}$ has the ability to provide, direct coronal or sagittal scanning sections, which allows accurate delineation of the lingual musculature and the extent of tumor infiltration. M RI has serious limitations as a research tool for studies of speech or deglutition because of supine position of the patient which causes difficulty in feeding and al so M RI data acquisition is slow when compared with normal feeding and deglutition. ${ }^{4} \mathrm{~A}$ ccording to $\mathrm{M}$ auren Stone et al MRI imaging can explain normal as well as glossectomy movements of the tongue. ${ }^{6}$ There is a need for a greater understanding of the biomechanical and muscular mechanisms that underlie compensatory tongue motion in order to provide outcome data that can assist surgeons in planning and evaluating reconstructive surgery.

\section{Scanning Electron Microscope}

The SEM uses a focused beam of high energy electrons to generate a variety of signals at the surface of solid specimens. SEM is a well-established tool for in vitro study of the surface topography of tongue dorsum, the character and morphology of the different types of tongue papillae and distribution and morphology of bacteria on the papillated areas of the dorsum. ${ }^{6} \mathrm{M}$ any studies have been performed in different animals but in human more studies are required to know the efficacy of SEM on tongue. 


\begin{tabular}{cll}
\multicolumn{4}{c}{ Table 1: Advanced investigation methods and its applications in tongue disorders } \\
\hline S. no. & Name of advanced investigation method & Applications in tongue disorders \\
\hline 1. & Cineradiography & Position and shape \\
2. & Pulsed ultrasound & Arterial blood flow \\
3. & Computer-assisted tomography & Location of the lesion, nerve damage \\
4. & Isotopic scanning & Abnormal tissue detection \\
5. & Electromyography & Muscle function \\
6. & Magnetic resonance imaging & Muscle function \\
7. & Scanning electron microscopy & Surface topography dorsum of tongue \\
8. & Video microscopy & Surface and structure of lingual papillae \\
9. & Stereo microscopy & Tongue papillae, capillary network, taste pores \\
\hline
\end{tabular}

\section{Video Microscopy}

Video microscopy is useful for observation of the surface of tongue papillae. N egoro et al in 2004 conducted a study in 10 individuals for observation of tongue papillae by video microscopy and contact endoscopy to investigate their correlation with taste function and concluded that in the normal taste group, round-shaped papillae and clear blood vessels were observed with both microscopy and contact endoscopy. ${ }^{5}$ In the taste disorder group, flat and irregular papillae were observed with microscopy. B lood vessel flow of the papillae was observed to be poor with contact endoscopy. It can be used invivo for visualization of tongue papillae, their capillary network, and taste pores.

\section{Stereo Microscopy}

A stereo microscope is an optical microscope fitted with two sets of lenses, each positioned to view an object from a slightly different angle. The result is a three-dimensional image. In order to produce a clear, functional threedimensional image, a stereo microscope relies on reflected, exterior light sources to illuminate its subject, instead of the brighter plate lights that shine through the specimen on a standard microscopy. It is similar to video microscopy and can be used to study the tongue papillae, their capillary network, and taste pores.

\section{CONCLUSION}

As tongue diagnosis has played a prominent role in the subsequent treatment of disease, it has attracted an increasing amount of attention as various investigatory methods have been used to detect tongue abnormalities. Shape, size, motion and any disability are very well recorded by investigative techniques like cineradiography, MRI, ultrasonography, CAT, isotopic scanning techniques, electromyography and also different microscopic techniques to study anatomy and any type of abnormality in papillary surface can be very well appreciated. Such, modernized techniques are very helpful in accurate diagnosis which leads to proper treatment.

To summarize, all the advanced investigation methods and its applications in tongue disorders have been mentioned in Table 1.

\section{CLINICAL SIGNIFICANCE}

The tongue is meant to be a trustw orthy mirror of the health and it is believed that the general health of a person is reflected in his tongue. It has attracted an increased amount of attention these days due to the various diseases involving the tongue. The advanced investigation methods are extremely hel pful for the proper diagnosis of these diseases. It also plays an important role in evaluating many muscular disorders associated with improper functioning of the tongue. They are very useful to the dental clinician in diagnosing unpredictable involvement and leads to the appropriate management of such diseases.

\section{REFERENCES}

1. Gans B. The fallacy of the furred tongue. B M ed J 1954;13: 1146.

2. Thexton A, Hiiemae K M. The effect of food consistency in jaw movement in the macaque: A cieneradiographic study. J Dent Rec 1974;76(1):552-60.

3. Keller E. Computerized measurement of tongue dorsum movements with pulsed-echo ultrasound. J A coust Soc Am 1984;3(4):1308-15.

4. Hiiemae KM, Palmer JB. Tongue movements in feeding and speech. Crit Rev Oral Biol M ed 2003;14(6):413-29.

5. N egoro A, U memoto M, Fukazawa K, Terada T, Sakagami M . O bservation of tongue papillae by video microscopy and contact endoscopy to investigate their correlation with taste function. A uris N asus Larynx 2004;31(3):255-59.

6. Pulvermuller F, Huss M, K heriff K, del Prado M artin FM, Hauk 0 , Shtyrov $Y$. M otor cortex maps articulatory features of speech sounds. PNA S 2006;103(20):7865-70.

7. Picoli LC, Lopes RA, Semprini M, Sala MA, Ogawa K, $W$ atanabe I-S. Transmission electron microscopy study of the neonatal rat tongue mucosa treated with special attention to the bacteriae on the epithelial cell membrane. Int J M orphol 2006;24(2):159-63. 
8. Maciocia G. Clinical aspects of tongue diagnosis. J Chinese Medicine 1995;48:17-20.

9. Altura A, L inguales PV . A nalysis of the height of lingual vallates papillae in Brazilian individual. Int J M orphol 2006;24(1):39-42.

10. Jones B, Buchholz DW, Ravich WJ, D onner M W. Swallowing dysfunction in postpolio syndrome: A cineflourographic study. AJR 1992;158:283-86.

11. Gaeddes DT, K ent J C, M itoulas LR, Hertmann PE. Tongue movements and intraoral vacuum in breastfeeding infants. Early Hum Dev 2008;84:471-77.

12. Buvat I, Hapdey S, B enali H, Todd-Pokropek A, Paola RD. Spectral factor analysis for multi-isotope imaging in nuclear medicine. IPM I 1999;1613:442-47.

13. M urakami R, Baba $Y, N$ ishimura $R$, Furusawa $M, B$ aba $T$, Okuda $T$, et al. CT and MR findings of denervated tongue after radical neck dissection. Am J Neuroradiol 1997;18:747-50.

14. Bathi R, Taneja N, Rao R. Lingual thyroid - A case report with brief review of literature. JIA OM R 2006;18(2):109-18.

15. Cheng S, Butler JE, Gandevia SC, Bilston LE. M ovement of the tongue during normal breathing in awake healthy humans. J Physio 2008;586(17):4283-94.

16. Hajiha M, DuBord MA, Liu H, Horner RL. Opioid receptor mechanisms at the hypoglossal motor pool and effects on tongue muscle activity in vivo. J Physiol 2009;587(11):2677-92.

\section{ABOUT THE AUTHORS}

\section{Neeraj Taneja}

Professor and Head, Department of Oral Medicine and Radiology BRS Dental College and Hospital, Sultanpur, Panchkula, Haryana India

Correspondence Address 1451, A TS Golf M eadows A partments Barwala Road, Dera Bassi, M ohali-140507, Punjab, India, Phone: 09815901670, e-mail: drntaneja@ rediffmail.com

\section{Srinivasa Raju}

Professor and Head, Department of Oral Medicine and Radiology Saraswati Dental College, Lucknow, Uttar Pradesh, India

\section{Rajul Mehta}

Senior Lecturer, Department of Oral M edicine and Radiology A hmedabad Dental College, A hmedabad, Gujarat, India

\section{Navdeep Kaur}

Postgraduate Student, Department of Oral M edicine and Radiology Teerthanker M ahaveer D ental College, M oradabad, U ttar Pradesh, India 